\title{
Spectrum of gynecological disorders in geriatric women: a tertiary care centre study
}

\author{
Baseerat Kaur*, Shashi Gupta, Sudesh Kumar, Shivali Sharma, Manvi Verma
}

Department of Obstetrics and Gynecology, SMGS Hospital, GMC Jammu, Jammu and Kashmir, India

Received: 26 September 2017

Accepted: 06 October 2017

\section{*Correspondence:}

Dr. Baseerat Kaur,

E-mail: sasansheeti@gmail.com

Copyright: (C) the author(s), publisher and licensee Medip Academy. This is an open-access article distributed under the terms of the Creative Commons Attribution Non-Commercial License, which permits unrestricted non-commercial use, distribution, and reproduction in any medium, provided the original work is properly cited.

\begin{abstract}
Background: Older women constitute the fastest growing segment of Indian population. Postmenopausal phase is important and primary care physicians should be aware of common gynaecologic concerns and the potential impact of these on the function and quality of life of older women.

Methods: A Prospective cross-sectional study was conducted over a period of one year on 100 postmenopausal women aged 65 years or above, who attended OPD or were hospitalised between November 2015 and October 2016.

Results: Literacy rate was $30 \%$. Study population was drawn equally from rural and urban population. Genital tract malignancy was the major gynecological disorder (32\%), the commonest being the carcinoma cervix. Next in order was carcinoma ovary and carcinoma endometrium. This was followed by pelvic organ prolapse (26\%) and urogenital infections (17\%). POP was grade 3 in $85 \%$ patients.

Conclusions: Pelvic organ prolapse, genital tract malignancies and urogenital infections were the major gynecological problems faced by older women. Moreover, postmenopausal bleeding was a possible underlying cause of malignancy, of which carcinoma cervix tops the list, emphasizing the need for a screening programme in Indian women. There is urgent need to develop dedicated geriatric units and to encourage women to receive routine gynecological check-ups in the early post menopausal period that will enable early diagnosis and treatment.
\end{abstract}

Keywords: Geriatric gynecology, Genital malignancy, Pelvic organ prolapsed (POP)

\section{INTRODUCTION}

Geriatric gynaecology deals with gynaecological pathologies encountered in postmenopausal women aged 65 years and above. The Indian society which was pyramidal till 20th century is now on the verge of becoming a rectangular society- a society in which nearly all individual survive to advanced age and then succumb rather abruptly over a narrow age range centering around the age of $85 .^{1}$ Our success in postponing death has increased the upper segment of demographic contour. The average life expectancy in India is 68 years. ${ }^{2}$ The rate of increase in number of postmenopausal women is substantially faster in developing than developed world. The number of women aged 60 years has grown from $5.4 \%$ in 1951 to $7.8 \%$ in $2001 .^{2}$ It is estimated to increase to $12.4 \%$ of population by the year $2026 .^{3}$ The age-related geriatric problems have emerged significantly with enhanced longevity of life. These are attributed to the physiological changes seen in reproductive organs due to their altered hormonal mileu. The unique features of geriatric illnesses arechronicity and heterogeneity, greater severity and slow or sometimes no recovery. The various gynaecological disorders peculiar to ageing are pelvic organ prolapse, postmenopausal bleeding, gynaecological malignancies, urinary incontinence, genital tract infections, vulvovaginal disorders. The spectrum of gynecological disorders in India differ from those in developed world as there are no screening programmes for early detection 
and hardly any dedicated geriatric units. The purpose of the present study is to assess the various types of gynecological problems faced by older women in India and to emphasize the need of promoting screening programmes for early detection and treatment of cancers and establishment of geriatric units to meet the special need of this subset of population.

\section{METHODS}

The present prospective, observational, cross-sectional study was conducted in the postgraduate department of Obstetrics and Gynecology, SMGS Hospital, Government Medical College, Jammu over a period of one year from November 2015 to October 2016. Sample size included 100 subjects of aged 65 years and above who attended OPD or were hospitalised. Valid informed consent was taken. The study protocol was approved by the Ethics Committee of the institute. Patient demographics (age, education, marital status, place of residence), reproductive parameters (parity, age at menopause, type of menopause, years since menopause), medical history and details of all gynecological problems were recorded.

Health related quality of life was assessed by using Menopause Rating Scale (MRS). Thorough clinical and gynecological examination done. Routine investigations including a complete haemogram, blood biochemistry, urine examination, pelvic sonography and pap smear were done. CT Scan and MRI were done wherever necessary. The data was analysed by computer software IBM Statistical Package for Social Sciences (SPSS) version 20.0. The qualitative variables were assessed as mean \pm standard deviation. The quantitative variables were expressed as frequencies and percentages.

Pelvic organ prolapsed (POP) was graded as per the Baden-Walker system on a scale of 0 to 4 ; grade 0 was defined as no prolapse, grade 1 as prolapse halfway to hymen, grade 2 as prolapse upto hymen, grade 3 as prolapse halfway beyond the hymen, and grade 4 complete prolapse. $^{4}$ The degree of cystocele, uretherocele, rectocele, and enterocoele was also assessed. Postmenopausal bleeding (PMB) was defined as vaginal bleeding 12 months after spontaneous cessation of menstruation. Urinary incontinence was defined as involuntary leakage of urine. Urinary tract infection (UTI) was the presence of viable

\section{RESULTS}

Out of 100 patients, $85 \%$ belonged to age group $65-74$ years. The study population was drawn approximately equally from rural and urban areas. Only 30\% of the patients were literate. Geriatric women had higher number of pregnancies. Their mean age at menopause was 48 (SD, 4.9) years and mean duration of menopause was 21 (SD, 5.9) years. None of the women was on hormone replacement therapy and none of them were aware about it (Table 1,2).

Table 1: Patient demographics.

\begin{tabular}{|lll|}
\hline \multicolumn{1}{|c|}{ Age (Years) } & & $\%$ \\
\hline $65-74$ & 85 & 85 \\
\hline $75-84$ & 13 & 13 \\
\hline$\geq 85$ & 2 & 2 \\
\hline Parity & & \\
\hline P 0 & 1 & 1 \\
\hline P 1-3 & 19 & 19 \\
\hline P 4-6 & 52 & 52 \\
\hline P 7-14 & 28 & 28 \\
\hline Educational status & & \\
\hline Illiterate & 70 & 70 \\
\hline Literate & 30 & 30 \\
\hline Background & & \\
\hline Rural & 56 & 56 \\
\hline Urban & 44 & 44 \\
\hline
\end{tabular}

Table 2: Distribution of patients according to mean age, mean age at menopause, mean duration of menopause.

\begin{tabular}{|l|l|}
\hline & Mean \pm standard deviation \\
\hline Age (years) & $69.64 \pm 4.97$ \\
\hline Age at menopause & $48.11 \pm 3.36$ \\
\hline Years since menopause & $21.40 \pm 5.94$ \\
\hline
\end{tabular}

The mean MRS score was 12.45 on a scale of 0 to 44 . This indicates that severity of menopausal symptoms decreases as the age advances.

Table 3: Chief presenting complaint.

\begin{tabular}{|l|l|}
\hline Chief Complaint & Number (n) \\
\hline SCOV & 26 \\
\hline PMB & 33 \\
\hline Abdominal distension & 9 \\
\hline Pain lower abdomen & 10 \\
\hline Discharge per vaginum & 8 \\
\hline Dysuria & 4 \\
\hline Backache/joint pains & 7 \\
\hline Vulval itching & 2 \\
\hline Vulval growth & 1 \\
\hline Total & 100 \\
\hline
\end{tabular}

Something coming out of vagina (SCOV, 26\%) and Postmenopausal bleeding (PMB, 33\%) were the two major presenting complaints (Table 3 ).

Amongst the co-morbidities, Hypertension (38) was the single most common followed by Anaemia (14), Diabetes mellitus (10), Thyroid disorders (9), Heart diseases (8). Presence of multiple co-morbidities complicates the diagnosis, treatment and natural course of individual 
gynaecological health problems in older women (Table 4).

Table 4: Associated co-morbidities.

\begin{tabular}{|ll|}
\hline Comorbidity & Number (n) \\
\hline Hypertension & 38 \\
\hline Anaemia & 14 \\
\hline Diabetes mellitus & 10 \\
\hline Thyroid disorders & 9 \\
\hline Heart disease & 8 \\
\hline COPD & 5 \\
\hline Asthma & 4 \\
\hline Others & 6 \\
\hline Total & 93 \\
\hline
\end{tabular}

The most common gynaecological disorder was genital tract malignancies $(32 \%)$, followed by POP (26\%) and urogenital infections (17\%). PMB was the major chief complaint and the underlying cause was malignancy in $70 \%$ of patients. Of those with genital malignancies, 16 (50\%) had carcinoma cervix, 9 (28\%) had carcinoma ovary, $6(19 \%)$ had carcinoma endometrium, and $1(3 \%)$ had carcinoma vulva. Amongst those with POP, $85 \%$ had $3^{\text {rd }}$ degree prolapse, $58 \%$ had associated cystocele and rectocele, and $2 \%$ had associated stress urinary incontinence. Of the $17 \%$ urogenital infections, $7 \%$ had pelvic inflammatory disease, $6 \%$ had vaginitis and $4 \%$ had UTI. Benign adnexal masses seen in $7 \%$ (serous cystadenoma $=5$, mucinous cystadenoma $=1$, dermoid $=1$ ) (Table 5).

Table 5: Gynecological disorders.

\begin{tabular}{|lll|}
\hline Pelvic organ prolapse (POP) & 26 & 26 \\
\hline Genital malignancies & 32 & 32 \\
\hline -Carcinoma cervix & 16 & 16 \\
\hline -Carcinoma endometrium & 6 & 6 \\
\hline -Carcinoma ovary & 9 & 9 \\
\hline -Carcinoma vulva & 1 & 1 \\
\hline Benign adnexal masses & 7 & 7 \\
\hline Urogenital infections & 17 & 17 \\
\hline Urinary incontinence & 2 & 2 \\
\hline Endometrial hyperplasia & 4 & 4 \\
\hline Proliferative endometrium & 1 & 1 \\
\hline Atrophic endometrium & 1 & 1 \\
\hline Endometrial polyp & 2 & 2 \\
\hline Cervical polyp & 1 & 1 \\
\hline Vulval papilloma & 1 & 1 \\
\hline Osteoporosis & 7 & 7 \\
\hline Pseudomyxoma peritonei & 1 & 1 \\
\hline Total & 100 & 100 \\
\hline
\end{tabular}

\section{DISCUSSION}

In present study, the mean age at menopause was 48 , which is comparable to that for north Indian women. ${ }^{5}$ Literate women comprised $30 \%$. The lower literacy rate and lack of health education in geriatric women make them less aware about the screening programmes and medical facilities available. Consequently, they report to hospitals only when symptomatic. POP, genital malignancies, and urogenital infections comprises $70 \%$ of all gynecological disorders in present study.

PMB in older women should be considered a sign of underlying genital cancer and warrants thorough evaluation. In our study, the underlying cause of PMB was malignancy in $70 \%$ cases.

Studies have shown that there is a significant increase in the incidence of cancer after 65 years of age. In western world, endometrial cancer was commonest genital malignancy, followed by ovarian malignancy. ${ }^{6}$ This was in contrast to our population, where carcinoma cervix was most common followed by ovarian and endometrium, in that order. Detection of carcinoma cervix at advanced stages was due to lack of screening programmes.

Uneducated women with low socioeconomic status coupled with cursory clinical evaluations they usually undergo at primary health centres lead to delay in presentation and diagnosis. The effectiveness of screening programmes against cervical cancer can be well judged by analysing the low incidence of malignancy as a cause of postmenopausal bleeding in Sweden, where prior to screening programme, $30 \%$ of Swedish women with postmenopausal bleeding had an underlying malignancy, of which one third was carcinoma cervix. The scenario depicted in present study resembles that of Sweden study prior to cervical cancer screening.

In present study, POP was present in $26 \%$ patients, out of which $85 \%$ were classified as grade 3 . This shows that the symptoms forced them to seek medical attention. About $50 \%$ of parous women lose pelvic floor support with advancing age. ${ }^{7}$

Pelvic floor dysfunction is a major health issue for older women, and the likelihood of undergoing an operation for POP by the age of 80 years was $11 \% .^{8}$ Olsen AL et al, showed in their study that the age-specific incidence of genital prolapse increased with advancing age and most patients were older, postmenopausal, parous, and overweight. $^{8}$ This was similarly found in our study. Estrogen receptors are widely present in the tissues that form the pelvic floor. Rizk et al. argued that postmenopausal estrogen deficiency has adverse effects on biologic ageing and pelvic floor support mechanism. ${ }^{9}$

In urogenital disorders, UTI and other infection like candida vaginitis, trichomonas and mixed infections are common because of vaginal $\mathrm{pH}$ changes owing to lack of estrogen. Ineffective voiding and incomplete bladder emptying leads to urinary stasis and colonisation by pathologic bacteria resulting in UTI. ${ }^{10}$ 


\section{CONCLUSION}

Postmenopausal period is an important part of a woman's life. The geriatric phase is even more important as ageing also becomes a factor. The changes in tissue milieu due to ageing causes difficulties in the application of treatment procedures posing an additional obstacle. Thus, caring for these women in their reproductive years as well as in later life should be an aim for all gynaecologists. The high incidence of carcinoma cervix in our set up emphasize the urgent need for screening programmes for postmenopausal women. In future, geriatric gynaecology will play an important role in India, as elderly population is demographically expanding. It is suggested that establishment of geriatric clinics in the current primary health care system can centralize attention to menopausal women and their needs. There is a necessity of multidisciplinary approach to the problems of menopause with more stress on preventions and interventions. The geriatric clinic is poised to meet these new challenges and provide opportunities to help patients live healthier lives.

\section{ACKNOWLEDGMENTS}

Authors would like to thank all patients for their cooperation.

Funding: No funding sources Conflict of interest: None declared

Ethical approval: The study was approved by the Institutional Ethics Committee

\section{REFERENCES}

1. Fritz MA, Speroff L. Menopause and the Perimenopausal Transition. In: Clinical Gynaecologic Endocrinology and Infertility. 8th ed. Philadelphia, PA: Wolters Kluwer (India) Pvt Ltd, New Delhi.
2. New Delhi: Census of India. censusindia.gov.in. C2001. Available at http://www.censusindia.gov.in/Census_Data_2001/In dia_at_glance/broad.aspx, accessed April 5, 2011.

3. Situation Analysis of The Elderly in India. Central Statistics Office, Ministry of Statistics \& Programme Implementation. Government of India. c2011 - [cited 2011 June]. Available at http://mospi.nic.in/mospi_new/upload/elderly_in_ind ia.pdf, accessed on April5, 2011.

4. Baden WF, Walker TA. Genesis of the vaginal profile: a correlated classification of vaginal relaxation. Clin Obstet Gynecol. 1972;15:1048-54.

5. Kriplani A, Banerjee K. An overview of age of onset of menopause in northern India. Maturitas. 2005;52:199-204.

6. Jamal A, Siegel R, Ward E, Murray T, Xu J, Smigal C, et al. Cancer statistics, 2006. CA Cancer J Clin 2006;56:106-30.

7. Beck RP. Pelvic relaxational prolapse. In: Kase NG, Weingold $\mathrm{AB}$, editors. Principles and practice of clinical gynaecology. New York: Wiley \& sons; 1983:677-85.

8. Oslen AL, Smith VJ, Bergstrom JO, Colling JC, Clark AL. Epidemiology of surgically managed pelvic organ prolapse and urinary incontinence. Obstet Gynecol. 1997;89:501-6.

9. Rizk DE, Fahim MA. Ageing of the female pelvic floor: towards treatment a la carte of the "geripause". Int Urogynecol J Pelvic Floor Dysfunct. 2008;19:455-8.

10. Magon N, Kalra B, Malik S, Chauhan M. Stress urinary incontinence: what, when, why, and then what? J Midlife Health. 2011:2(2):57-64.

Cite this article as: Kaur B, Gupta S, Kumar S, Sharma S, Verma M. Spectrum of gynecological disorders in geriatric women: a tertiary care centre study. Int J Reprod Contracept Obstet Gynecol 2017;6:4869-72. 